\title{
Overexpression of Metallothionein in the Heart of Transgenic Mice Suppresses Doxorubicin Cardiotoxicity
}

\author{
Y. James Kang, ${ }^{\star}$ Yan Chen, ${ }^{\star}$ Anding Yu, ${ }^{\star}$ Mildred Voss-McCowan, ${ }^{\ddagger}$ and Paul N. Epstein ${ }^{\ddagger}$ \\ $*$ Department of Medicine, University of Louisville School of Medicine, Louisville, Kentucky 40292; ${ }^{*}$ Department of Pharmacology and \\ Toxicology, University of North Dakota School of Medicine, Grand Forks, North Dakota 58202
}

\begin{abstract}
Metallothionein (MT) may provide protection against doxorubicin-induced heart damage. To test this hypothesis, a heart-specific promoter was used to drive the expression of human MT-IIa gene in transgenic mice. Four healthy transgenic mouse lines were produced. Cardiac MT was constitutively overexpressed from 10- to $\mathbf{1 3 0 - f o l d ~ h i g h e r ~ t h a n ~ n o r - ~}$ mal. The MT concentration was not altered in liver, kidneys, lungs, or skeletal muscles. Other antioxidant components including glutathione, glutathione peroxidase, glutathione reductase, catalase, and superoxide dismutase were not altered in the MT-overexpressing heart. Mice (7-wk-old) from transgenic lines expressing MT activity 10- or 130 -fold higher than normal and from nontransgenic controls were treated intraperitoneally with doxorubicin at a single dose of $20 \mathrm{mg} / \mathrm{kg}$, and were killed on the 4th day after treatment. As compared to normal controls, transgenic mice exhibited a significant resistance to in vivo doxorubicin-induced cardiac morphological changes, and the increase in serum creatine phosphokinase activity. Atria isolated from transgenic mice and treated with doxorubicin in tissue bath was also more resistant to functional damage induced by this drug. The results provide direct evidence for the role of MT in cardioprotection against doxorubicin toxicity. (J. Clin. Invest. 1997. 100:1501-1506.) Key words: contractility • creatine phosphokinase $\cdot$ electron microscopy $\bullet$ morphology $\bullet$ transgene
\end{abstract}

\section{Introduction}

Doxorubicin is an anthracycline antibiotic, and is one of the most important anticancer agents. It is effective in treatment of acute leukemias and malignant lymphomas as well as a number of solid tumors. Cardiotoxicity, however, compromises the

This work was presented in part at the 35th Annual Meeting of the Society of Toxicology, and at the 87th Annual Meeting of the American Association for Cancer Research.

Address correspondence to Dr. Y. James Kang, Department of Medicine, University of Louisville School of Medicine, 530 S. Jackson St., Louisville, KY 40202. Phone: 502-852-6991; FAX: 502-852-0846; E-mail: yjkang01@homer.louisville.edu

Received for publication 28 March 1997 and accepted in revised form 1 July 1997.

J. Clin. Invest.

(C) The American Society for Clinical Investigation, Inc. 0021-9738/97/09/1501/06 \$2.00

Volume 100, Number 6, September 1997, 1501-1506

http://www.jci.org clinical use of doxorubicin (1-3). Studies have suggested that doxorubicin may have at least two mechanisms of action that cause cellular damage. One involves generation of oxygen free radicals, the damage from which is inhibited by free radical scavengers. These free radicals appear to play a major role in the development of cardiomyopathy (4-7). The other is mediated by the intercalation of the drug to DNA, and is unaffected by free radical scavengers. This appears to be the major determinant of doxorubicin cytotoxicity to tumor cells (7).

Metallothionein (MT) ${ }^{1}$ is a highly conserved, low-molecular-weight, thiol-rich protein. Because MT can both bind to and be induced by heavy metal ions, it is generally agreed that MT is somehow related to metal metabolism and toxicity (8). Recent studies (9) have suggested that MT also plays a role in the scavenging of free radicals. Importantly, preinduction of MT by bismuth subnitrate decreases doxorubicin cardiotoxicity (10). Zinc, cadmium, cobalt, or mercury were used to substitute the inducing agent, and a decrease in doxorubicinrelated myocardial lipid peroxidation in correlation to MT induction was seen in each case (10).

These agents, however, are not specific for MT induction, and therefore, cytoprotection may have been due to other effects of the inducing agents. These could include activation or induction of other stress responses or repair systems, changes in cellular metabolic and transport processes, and delays in cell cycling. Factors such as stress proteins and glutathione, which are inducible by heavy metals and other stresses, have been frequently shown to be involved in resistance to free radicals in animals. In addition, these inducing agents are not tissue-specific. Detoxification may occur in other tissues affected by these inducers, such as in the liver, where MT is often highly induced. Therefore, the observed decrease in cardiotoxicity may be simply due to changes in metabolism or/and shifts in pharmacokinetics of the drug.

In this study, we have developed a transgenic mouse model in which MT is overexpressed only in the heart. To determine whether MT elevation provides in vivo protection against doxorubicin cardiotoxicity, morphological changes in myocardial tissues were examined by electron microscopy, and serum creatine phosphokinase activities were determined in the doxorubicin-treated transgenic mice. In addition, the atria isolated from the transgenic mice and nontransgenic controls were used to determine the effect of MT on doxorubicin-induced functional changes. All of our results demonstrate that overexpression of MT in the heart provides protection against doxorubicin cardiotoxicity.

1. Abbreviations used in this paper: CPK, creatine phosphokinase; GR, glutathione reductase; GSHpx, glutathione peroxidase; MHC, myosin heavy chain; MT, metallothionein; SOD, superoxide dismutase. 


\section{Methods}

Generation and identification of cardiac MT-overexpressing transgenic mice

FVB mice obtained from the University of North Dakota Biomedical Research Center were used to produce transgenic lines. All animal procedures were approved by the AAALAC certified institutional animal care committee. A 11.4-kb transgene designated MyMT-IIa was constructed for overexpression of MT in cardiac tissue of transgenic mice. This transgene contains all of the coding sequences of the human MT-IIa gene, which included the MT start and stop codons (11). Transcription of the transgene is controlled by a fragment of the mouse alpha cardiac myosin heavy chain (MHC) gene previously used by Gulick et al. (12) to produce high-level, cardiac-specific expression of cDNA constructs in transgenic mice. The MHC fragment includes the MHC promoter $(5 \mathrm{~kb})$, the first two introns, and the first three noncoding exons of the MHC gene (12). Standard procedures (13) were used for development of transgenic mice. The 11.4-kb MyMT-IIa transgene was purified (14) on a matrix of diatemaceous earth (Prepagene; Bio-Rad Laboratories, Richmond, CA) and filtered through a $0.22-\mu \mathrm{m}$ filter. Approximately 100 copies of the purified transgene were microinjected into one pronucleus of each onecell mouse embryo of the inbred strain FVB (15). 20 microinjected embryos were implanted into each Avertin-anesthetized pseudopregnant female and allowed to come to term. To identify transgenic founder mice, genomic DNA was isolated from 1-cm tail clips from 3-4-wk-old mice. DNA was subjected to Southern and dot blot analyses that were probed with an 850-bp Nco I/Bgl II fragment derived from the human MT-IIa gene of the MyMT-IIa transgene. This probe hybridized to a 11.5-bp Sac I fragment of the genomic DNA digests, consistent with the presence of a unique Sac I site in the MyMT-IIa transgene. The same probe was also used for Northern analysis of the MT mRNA in the transgenic mouse heart. Founder mice were bred with mice of the same strain, and transgenic offspring were routinely identified by PCR using a primer pair derived from the MHC promoter and human MT-IIa gene. Transgenic positive mice (heterozygotes) and negative littermates were then used for experiments.

\section{Biochemical characterization of the transgenic mice}

Preparation of tissue samples. Animals were anesthetized with an intraperitoneal injection of sodium pentobarbital $(65 \mathrm{mg} / \mathrm{kg}$ body weight; Vet Labs, Lenexa, KS). To avoid the contribution of the RBCs remaining in the heart to the measured parameters, the heart of anesthetized mice was perfused with $20 \mathrm{ml}$ saline (room temperature). A cannulated needle $(25 \mathrm{G} 3 / 8)$ was inserted $\sim 3 \mathrm{~mm}$ into the left ventricle. The inferior vena cava was punctured to allow blood and saline to wash out. The heart was then removed. Liver, lung, and kidney were excised and flushed with cold saline via their major vessels. Tissue samples were placed in liquid nitrogen and then stored at $-80^{\circ} \mathrm{C}$ for $<36 \mathrm{~h}$ before analyses as described below.

Metallothionein. Total tissue MT concentrations were determined by the cadmium-hemoglobin affinity assay (16). In brief, tissues were homogenized in $4 \mathrm{vol}$ of $10 \mathrm{mM}$ Tris- $\mathrm{HCl}$ buffer, $\mathrm{pH}$ 7.4, at $4^{\circ} \mathrm{C}$. After centrifugation of the homogenate at $10,000 \mathrm{~g}$ for $15 \mathrm{~min}$, $200 \mu \mathrm{l}$ supernatant was transferred to microtubes for MT analysis, and $100 \mu \mathrm{l}$ was transferred to separate microtubes for protein analysis. Samples were then prepared for MT determination as described previously (16).

Superoxide dismutase (SOD). The enzyme activity was assayed as described by Nebot et al. (17). A SOD-525 assay kit based on this method was obtained from BioxyTech S.A. (Bonneuil Sur Marne, Cedex, France). Detailed procedure was described previously (34). The enzyme activity is expressed as units per $\mathrm{g}$ wet tissue.

Catalase. The enzyme activity was determined by the method of Aebi (18) as described previously (34). Specific activity is expressed as $\mu \mathrm{mol} \mathrm{H}_{2} \mathrm{O}_{2} /$ min per $\mathrm{mg}$ of protein (19).

GSH peroxidase (GSHpx). The enzyme activity was determined by the method described by Flohe and Gunzler (20). Specific activity is expressed as $\mathrm{nmol} \mathrm{NADPH} / \mathrm{min}$ per $\mathrm{mg}$ of protein as described previously (34).

$G S H$ reductase $(G R)$. The enzyme activity was determined by the method described by Carlberg and Mannervik (21). Specific activity is expressed as nmol NADPH/min per $\mathrm{mg}$ of protein.

Glutathione (GSH and GSSG). Tissues were homogenized in 10 vol of $5 \%(\mathrm{wt} / \mathrm{vol}) 5$-sulfosalicylic acid at $4^{\circ} \mathrm{C}$. The homogenate was centrifuged at $10,000 \mathrm{~g}$ for $15 \mathrm{~min}$, and the supernatant was assayed for GSH by the DTNB-glutathione reductase recycling assay (22). The 1.0-ml reaction mixture contained $190 \mu \mathrm{l}$ stock buffer $(143 \mathrm{mM}$ sodium phosphate and $6.3 \mathrm{mM} \mathrm{Na}_{4}$-EDTA, pH 7.5), $700 \mu \mathrm{l} 0.248 \mathrm{mg}$ $\mathrm{NADPH} / \mathrm{ml}$ in stock buffer, $100 \mu \mathrm{l} 6 \mathrm{mM}$ DTNB, and $10 \mu \mathrm{l}$ sample. The assay was initiated by addition of $10 \mu \mathrm{l}$ of $266 \mathrm{U}$ glutathione reductase $/ \mathrm{ml}$. Standards were assayed in parallel under the same conditions as tissue samples.

\section{Determination of doxorubicin cardiotoxicity}

Transgenic mice and normal controls (7-wk-old, without regard to sex because our preliminary studies showed no difference in cardiac toxic responses to doxorubicin between males and females) were injected i.p. with doxorubicin hydrochloride (Sigma Chemical Co., St. Louis, MO) at $20 \mathrm{mg} / \mathrm{kg} .4 \mathrm{~d}$ after receiving the doxorubicin injection, the experimental animals were anesthetized with sodium pentobarbital $(65 \mathrm{mg} / \mathrm{kg}$ body weight i.p., Vet Labs), and cardiotoxicity was determined as described below. The operators were unaware of the transgenic and doxorubicin treatment status of the mice at the time of EM morphological and atrial functional examinations.

Morphological changes examined by electron microscopy. The heart of anesthetized mice was perfused in situ as follows: into the cardiac apex a cannulated needle ( $25 \mathrm{G} \mathrm{3/8}$, silastic medical grade, 0.02 " ID and $0.037^{\prime \prime} \mathrm{OD}$ ) was inserted $\sim 3 \mathrm{~mm}$. The heart was perfused with a wash-out solution ( $6.6 \mathrm{~g}$ paraformaldehyde dissolved in $500 \mathrm{ml}$ distilled water; $1.6 \mathrm{ml} 50 \%$ glutaraldehyde; $360 \mathrm{ml} 0.2 \mathrm{~N}$ sodium cacodylate buffer, $\mathrm{pH} 7.2-7.4 ; 0.5 \mathrm{~g} \mathrm{CaCl}_{2} ; 0.25 \mathrm{~g} \mathrm{AlCl}_{3} ; 1.0 \mathrm{~g}$ procaine hydrochloride; add water to make final volume of $1,000 \mathrm{ml}$, room temperature) at a flow rate of $5 \mathrm{ml} / \mathrm{min}$ for 2-3 min until the wash-out fluid became clear. This was followed by a Karnovsky's fixative $(10 \mathrm{~g}$ paraformaldehyde dissolved in $500 \mathrm{ml}$ distilled water; $50.0 \mathrm{ml} 25 \%$ glutaraldehyde; $360 \mathrm{ml}$ of $0.2 \mathrm{~N}$ sodium cacodylate buffer, $\mathrm{pH}$ 7.2-7.4; $0.5 \mathrm{~g} \mathrm{CaCl}_{2} ; 0.25 \mathrm{~g} \mathrm{AlCl}_{3}$; add water to make final volume of $1,000 \mathrm{ml}$ ) at a rate of $3 \mathrm{ml} / \mathrm{min}$ for $10 \mathrm{~min}$ at $4^{\circ} \mathrm{C}$. The heart was removed and immersed into precooled $\left(4^{\circ} \mathrm{C}\right)$ Karnovsky's fixative immediately. The left ventricle (LV) and interventricular septum (IVS) were dissected, and cut into $1-\mathrm{mm}^{3}$ sections with a razor blade. Six pieces each of LV and IVS were placed into a vial filled with precooled Karnovsky's fixative at $4^{\circ} \mathrm{C}$ for $90 \mathrm{~min}$, and rinsed three times with $0.2 \mathrm{~N}$

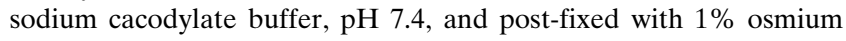
tetroxide at $4^{\circ} \mathrm{C}$ in dark for $90 \mathrm{~min}$ (osmium solution was mixed in the following way: one part of $2 \%$ osmium tetroxide to one part of $S$-collidine buffer, $\mathrm{pH}$ 7.4). The blockers were rinsed $3 \times$ with distilled $\mathrm{H}_{2} \mathrm{O}$, and were dehydrated with ethanol and propylene oxide on the following schedule: ethanol 50\%, $5 \mathrm{~min} ; 70 \%, 5 \mathrm{~min} ; 80 \%, 5 \mathrm{~min} ; 95 \%$, $10 \mathrm{~min} ; 100 \%, 20 \mathrm{~min}$; and propylene oxide $20 \mathrm{~min}$ for three times under hood. The blockers were infiltrated with propylene oxide/Epon Araldite (2/1) for one $\mathrm{h}$ (leave the cap loose), propylene oxide/Epon Araldite (1/2) for one $\mathrm{h}$, followed by Epon Araldite for one $\mathrm{h}$ or longer. The blocks were then embedded in flat embedding molds with fresh prepared Epon/Araldite, and were cured on the uncovered mold in a $55^{\circ} \mathrm{C}$ oven for $48 \mathrm{~h}$. Longitudinally and cross-sectionally oriented myocardial fibers were selected under light microscope (BH-2 Olympus Corp., Lake Success, NY) on semi-thin sections stained with $1 \%$ toluidine blue. Subsequently, ultrathin sections were stained with $2 \%$ uranyl acetate and $0.18 \%$ lead citrate and examined with JEM-100 S transmission electron microscopy (JEOL USA, Inc., Peabody, MA) operated at $80 \mathrm{kV}$.

Creatine phosphokinase (CPK) activity. Serum CPK activity was assayed as described by Oliver (23). A CPK Test kit (CK-20; Sigma Chemical Co.) based on this method was obtained from Sigma. Blood 
was collected from the inferior vena cava of the anesthetized animals, and serum was obtained by a serum separator apparatus (Becton Dickinson, Inc., Rutherford, NJ).

Atrial functional alteration. Mice were anesthetized with sodium pentobarbital. Atria were separated from ventricles and placed in a 30-ml chamber containing Krebs-Henseleit $(\mathrm{KH})$ buffer of the following composition: $\mathrm{NaCl}(118 \mathrm{mM}) ; \mathrm{KCl}(4.7 \mathrm{mM}) ; \mathrm{NaHCO}_{3}(3.0$ $\mathrm{mM}) ; \mathrm{CaCl}_{2}(3.0 \mathrm{mM}) ; \mathrm{MgSO}_{4}(1.2 \mathrm{mM}) ; \mathrm{KH}_{2} \mathrm{PO}_{4}(1.2 \mathrm{mM})$; glucose $(10 \mathrm{mM})$; and $\mathrm{Na}_{2}$ EDTA $(0.5 \mathrm{mM})$; pH 7.4 gassed with $5 \% \mathrm{CO}_{2}$ in $\mathrm{O}_{2}$. A preload tension of $0.25 \mathrm{~g}$ was applied. The atria were allowed to stabilize for $30 \mathrm{~min}$ before doxorubicin was added to the incubation buffer to a final concentration of $100 \mu \mathrm{M}$. The effect of doxorubicin on inotropy (contractile force) and chronotropy (heart rate) were determined using isolated left and right atrium, respectively. Cardiac inotropy and chronotropy were recorded isometrically by a Grass FT.03 force transducer and a Grass 7 recorder (Grass Instrument Co., Quincy, MA).

\section{Results}

Cardiac MT concentration was determined in six animals (three males and three females) of each transgenic line and nontransgenic controls. As shown in Fig. 1, MT was markedly elevated in the transgenic hearts. This elevation ranges from 10 -fold in line 12 to 130 -fold in line 1 . There was no significant difference $(P>0.10)$ in the MT concentration between males and females within the same transgenic line (data not shown). The level of mRNA for MT was also increased in the transgenic heart (data not shown). This overexpression was stable, as evidenced by consistent results obtained in several assays performed over $1 \mathrm{yr}$. To determine whether the elevated MT expression was specific to the heart, MT concentrations in liver, kidneys, lungs, and skeletal muscles of the transgenic mice were measured. The MT concentrations in all these tissues were the same as controls (data not shown).

We then determined whether other antioxidant enzyme activities in the transgenic heart were altered due to changes in MT concentration and/or genomic alteration. The activities of SOD, catalase, GSHpx, and GR were measured in the MT-

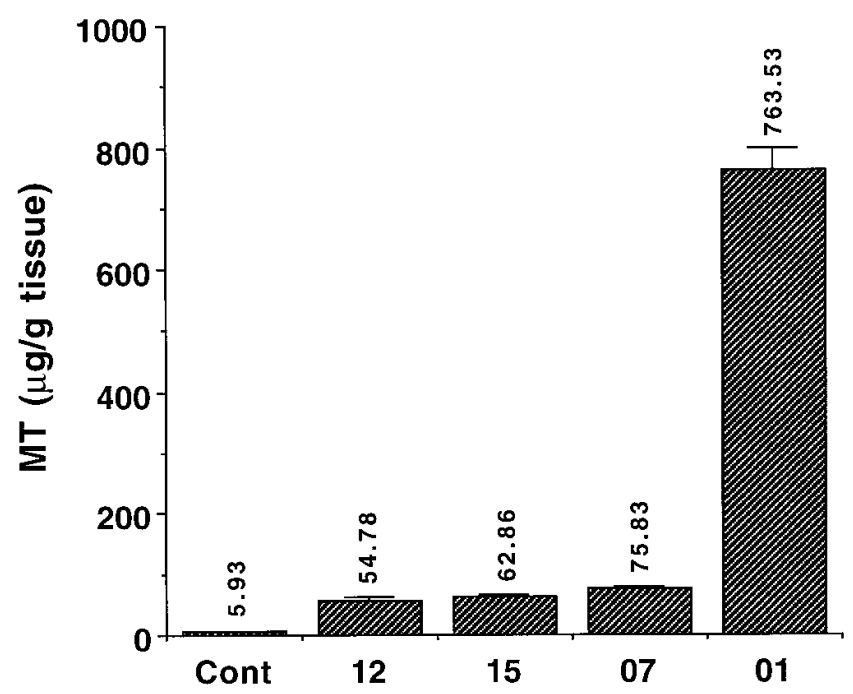

Figure 1. MT concentrations in the heart from each of the four different transgenic mouse lines $(12,15,07$, and 01$)$ in comparison with that of controls (Cont). Each value is the average of six determinations $($ mean $\pm \mathrm{SD})$.
Table I. Enzyme Activities of SOD, GSHpx, GR, and Catalase, and Concentration of GSH in the Hearts of Control and My-MT-IIa Transgenic Mice

\begin{tabular}{lcc}
\hline & Control & My-MT-IIa \\
\hline SOD (U/g tissue) & $98.6 \pm 11.7$ & $106.3 \pm 12.4$ \\
Catalase $\left(\mu \mathrm{mol} \mathrm{H} \mathrm{O}_{2} / \mathrm{min} \cdot \mathrm{mg}\right.$ protein) & $24.0 \pm 1.2$ & $25.5 \pm 1.2$ \\
GSHpx (nmol NADPH/min'mg protein) & $29.3 \pm 2.5$ & $26.6 \pm 3.3$ \\
GR $(\mathrm{nmol} \mathrm{NADPH} / \mathrm{min} \cdot \mathrm{mg}$ protein) & $14.2 \pm 1.5$ & $16.0 \pm 1.4$ \\
GSH $(\mu \mathrm{mol} / \mathrm{g}$ tissue $)$ & $1.3 \pm 0.1$ & $1.2 \pm 0.1$ \\
& & \\
\hline
\end{tabular}

The data were obtained from nontransgenic mice (control, $n=6$ ) and four transgenic mouse lines (lines 1, 7, 12, and 15). Three mice were used from each of the four lines, and the data were pooled together to give the average value (My-MT-IIa, $n=12$ ).

enriched transgenic hearts. As shown in Table I, none of these enzyme activities were altered. We also measured the concentration of GSH. There was no alteration in GSH in the MTenriched transgenic hearts (Table I).

Two transgenic lines were then selected to determine the effect of elevated MT levels on doxorubicin-induced oxidative damage to the heart. These two transgenic lines have cardiac MT concentrations about 10- or 130-fold higher than normal. Transgenic mice and nontransgenic controls were treated with a single dose of doxorubicin at $20 \mathrm{mg} / \mathrm{kg}$. $4 \mathrm{~d}$ after the treatment, the morphological changes in the myocardial tissue were examined by electron microscopy. As shown in Fig. 2, doxorubicin induced dramatic morphological changes in the nontransgenic mouse heart. Moderate nuclear chromatin margination with many pieces of coarse chromatin clumping was observed. Mitochondria showed severe swelling with membrane disruption, cristae disappearance, and matrix clearout. Myelin figures were also observed. Sarcoplasmic reticula were slightly dilated. In contrast to these findings, the chromatin was distributed homogeneously within the nucleus in the doxorubicin-treated MT-overexpressing transgenic mouse heart. Mitochondrial membrane and cristae were intact. No myelin figures were found. Therefore, there was no alteration in the morphology of myocytes in the doxorubicin-treated MT-overexpressing transgenic mouse heart. The same result was obtained with the transgenic hearts in which MT was overexpressed either 10-fold (Fig. 2) or 130-fold (data not shown) higher than normal.

Doxorubicin toxicity was also revealed by elevated serum CPK in nontransgenic mice (Fig. 3). MT overexpression 10fold higher than normal almost completely inhibited doxorubicin-induced elevation of serum CPK activity. Again, 130-fold elevation of MT in the heart showed the same protective effect (data not shown).

Isolated atria from transgenic mice overexpressing cardiac MT about 10-fold were used to determine the effect of doxorubicin on atrial function. When doxorubicin was added to the incubation buffer, atrial contractions were inhibited. To precisely determine the effect of MT on doxorubicin-reduced contractile force (inotropy) and heart rate (chronotropy), left and right atria were separated. The left atrium was paced by a stimulator at a fixed frequency of $4 \mathrm{~Hz}$ and a voltage of 1.5 times the threshold value. A 30-min equilibration period was applied. There was no significant difference in the contractile 

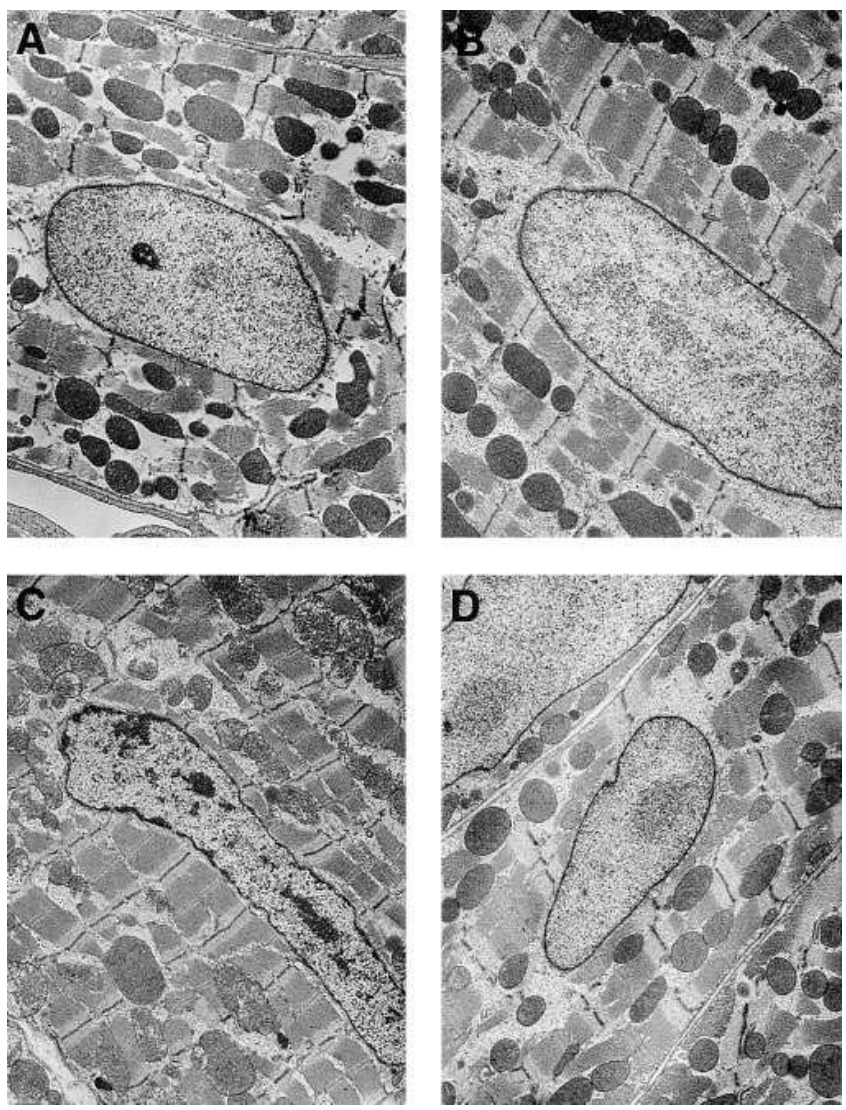

Figure 2. Electron micrograph showing the effect of elevated MT on doxorubicin-induced morphological changes in the myocardial tissue. $(A)$ Nontransgenic control treated with saline; $(B)$ transgenic control treated with saline; $(C)$ nontransgenic mouse treated with doxorubicin; $(D)$ transgenic mouse treated with doxorubicin. $\times 6,000$.

force between the transgenic atria and the normal controls; $0.52 \pm 0.02$ and $0.51 \pm 0.01 \mathrm{~g}$, respectively, nor did the contraction rate differ between the transgenic atria and the normal controls; $252 \pm 12$ beats/min and $246 \pm 26$ beats/min, respectively. Both contractile force and contraction rate remained stable for more than $4 \mathrm{~h}$ in the absence of doxorubicin. As shown in Fig. 4, 10-fold elevation of MT markedly suppressed doxorubicin-reduced inotropy (left atrium), but did not inhibit doxorubicin-reduced chronotropy (right atrium). The same result was obtained with the heart in which MT was overexpressed 130-fold higher than normal (data not shown).

\section{Discussion}

Cardiotoxicity has long been recognized as a complicating factor of cancer chemotherapy with doxorubicin. There are several hypotheses to explain doxorubicin cardiotoxicity. Among these, the free radical hypothesis has been thoroughly investigated. Doxorubicin undergoes one-electron reduction through a metabolic activation catalyzed by NADPH-cytochrome-P-450 reductase, or other flavin-containing enzymes (24). This reduction generates a doxorubicin semiquinone free radical. In the presence of molecular oxygen, the semiquinone rapidly reduces the oxygen to superoxide with regeneration of intact doxorubicin. Superoxide is rapidly converted to hydro-

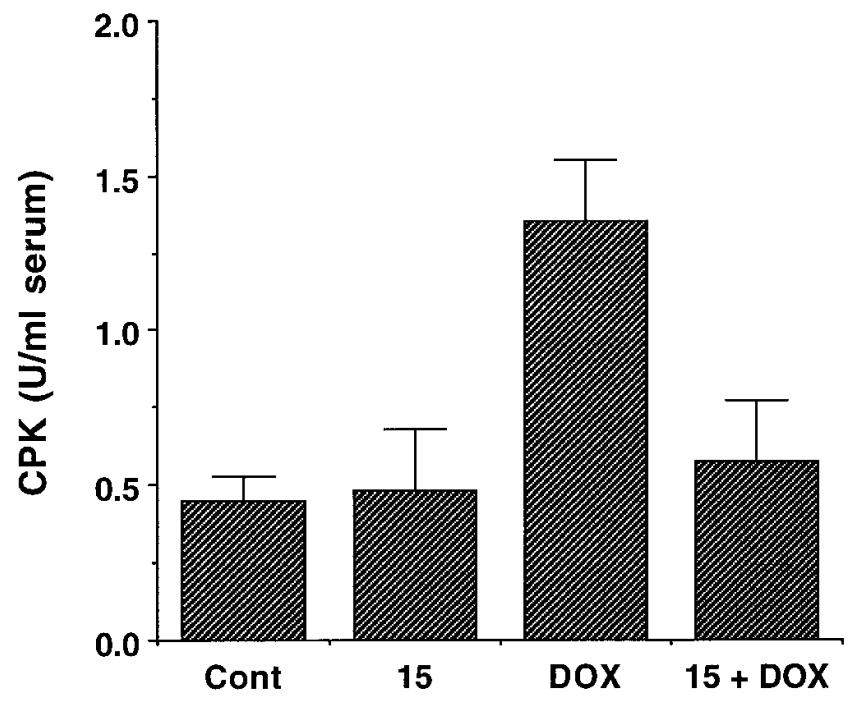

Figure 3. Doxorubicin-induced creatine phosphokinase (CPK) release from the heart. Serum CPK was measured using a CK-20 kit from Sigma Chemical Co. As shown, doxorubicin significantly increased serum CPK level in the nontransgenic control mice (DOX). Animals from transgenic line 15 (15) were used to determine the effect of MT on DOX-induced CPK release $(15+$ DOX). Elevation of MT in the heart completely inhibited the increase in the serum CPK level $(P<0.05)$.

gen peroxide spontaneously or by superoxide dismutase. The doxorubicin semiquinone can then react with the hydrogen peroxide to yield hydroxyl radical (25). These highly toxic reactive oxygen species react with cellular molecules including nucleic acids, protein, and lipids, thereby causing cell damage. Most supportive evidence for this free radical hypothesis has been obtained from in vitro studies, including reports that $(a)$ doxorubicin increased lipid peroxidation and free radical production in the heart tissue (26); $(b)$ free radical scavengers such as $N$-acetylcysteine (27), vitamin E (28), superoxide dismutase (28), and catalase (7) decreased the severity of doxorubicin-induced oxidative damage; $(c)$ suppression of antioxidant activities enhanced doxorubicin toxicity in cultured cardiac cells (29).

MT, due to its free radical scavenging capability, may play an important role in cardiac protection against doxorubicin cardiotoxicity. Previous studies have shown that preinduction of MT inhibited doxorubicin-induced heart damage (10). The experiments that used inducers to increase MT levels, however, have at least three shortcomings that limit both the result interpretation and its potential application to clinical situations. First, as discussed in the introduction, these inducers have many actions in addition to inducing MT, and these actions could alter the sensitivity of the heart to doxorubicin. Second, these agents are not specific to the heart, and extracardiac actions may influence doxorubicin pharmacokinetics and toxicity. Finally, the concentrations of induced MT are not stable, and vary during the course of the experiment. To overcome these limitations, we produced the cardiac-specific MT-overexpressing transgenic mouse model. These transgenic mice appear normal and healthy. The only alteration in their body is that their cardiac MT is overexpressed. This experimental model thus allows us to study unequivocally the role of MT in 

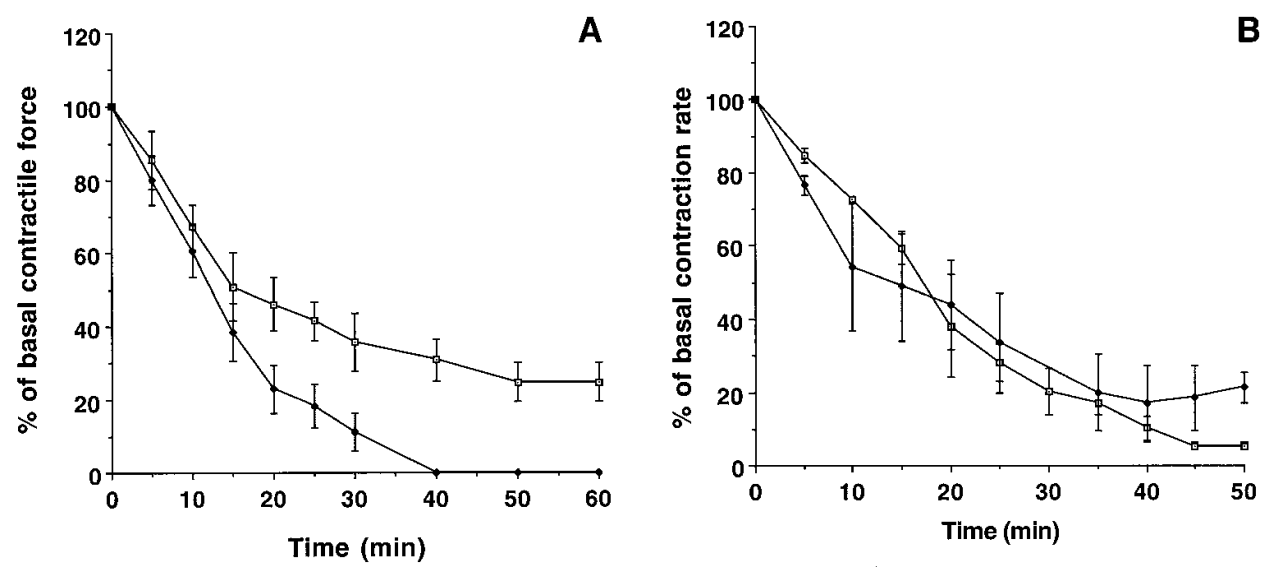

B Figure 4. Effect of MT elevation on doxorubicin-reduced inotropy $(A$, left atrium) and chronotropy $(B$, right atrium). Doxorubicin was added into the incubation buffer to a final concentration of $100 \mu \mathrm{M}$. The left atria were paced by a fixed frequency of $4 \mathrm{~Hz}$ and a voltage of 1.5 times the threshold value. The $x$-axis indicates time after doxorubicin incubation in the tissue bath. This measurement was repeated three times with atria isolated from different animals and consistent results were obtained. White squares, transgenic; black diamonds, control. protection against doxorubicin cardiotoxicity. The results from this study clearly demonstrated that elevation of MT in the heart provides protection against doxorubicin-induced injury.

Possible mechanisms for MT functions in cytoprotection against oxidative injury have been studied in vitro (9) and in cultured cells (30). It has been suggested that the cysteine residues of the MT were the primary target for the reaction of hydroxyl radicals with this protein (9). Alternatively, the primary determinant of MT protection is the release of its associated metal, zinc, and the subsequent uptake of zinc by the membrane (31), since zinc protects against lipid proxidation and thereby stabilizes membranes (32). Another possibility is that MT chelates iron, or otherwise mediates its conversion into a form that is not active as a Fenton reactant. The formation of an iron-MT complex in vitro has been described (33). MT may donate an $\mathrm{H}$ atom to a cellular target radical on a DNA molecule, restoring it to an undamaged state. It is unknown, however, whether MT functions in vivo as the same as in vitro. The experimental model produced in this study will be a valuable tool for such investigations.

In our previous studies, we have produced transgenic mice in which cardiac catalase was overexpressed (34). Catalase, like MT, was found to protect against doxorubicin cardiotoxicity. Significant and instructive differences, however, were found between the protections afforded by these two transgenes. Unlike MT protection, cardiac protection by catalase was highly dose-dependent. A 10-fold increase in catalase over normal levels provided no apparent protection. Maximum protection was reached by elevation of catalase in the heart about 100-fold, and 200-fold or greater elevation failed to provide protection. In this study, we found that overexpression of MT 10 -fold or 130-fold higher than normal provided the same extent of protection against doxorubicin cardiotoxicity. The current results suggest that 10 -fold elevation of MT in the heart may provide maximal cardiac protection against doxorubicin toxicity. This elevation, however, may not be the minimal level by which maximal protection can be achieved. The results also indicate that MT is more potent than catalase in cardiac protection against doxorubicin toxicity. Moreover, very high expression of MT in the heart did not diminish protection, in contrast to what was observed with catalase.

Another difference between catalase and MT protection was observed in the study of doxorubicin-induced alterations in atrial function. In our previous report with cardiac catalase overexpressing atria we found that elevation of catalase inhib- ited doxorubicin-induced alterations in both heart rate and contractile force. In this study, however, MT inhibited only doxorubicin-reduced contractile force. MT is a potent scavenger of hydroxyl radical (9). Catalase, on the other hand, reacts with hydrogen peroxide. It is possible that the heart rate change is more related to hydrogen peroxide's toxicity. Alternatively, metabolism of doxorubicin, and thereby production of reactive oxygen species, may not occur in pacemaker cells. Also, neither catalase nor MT would be overexpressed in these cells of the transgenic mice because of the promoter used. Thus, direct oxidative damage and antioxidant reactions may not occur in the pacemaker cells. Hydrogen peroxide, however, is diffusible, and it is possible that hydrogen peroxide generated in myocytes diffuses into pacemaker cells, and is converted to hydroxyl radical in these cells to cause chronotropic toxicity. In the presence of catalase, hydrogen peroxide would be destroyed before diffusing, and therefore the pacemaker cells would be protected indirectly by catalase. MT, on the other hand, reacts primarily with hydroxyl radical in the myocytes. It would not prevent hydrogen peroxide diffusing into the pace maker cells. These hypotheses will be tested in our future studies.

The results obtained from this study provide direct in vivo evidence showing that MT functions in protection against doxorubicin cardiotoxicity, and further support the free radical hypothesis of doxorubicin cardiotoxicity. More importantly, the effective level of MT in the heart to prevent doxorubicin toxicity was defined to be less than 10 -fold over normal. This level may be achieved pharmaceutically. For instance, bismuth subnitrate induces MT synthesis in mouse heart to reach severalfold higher than normal and reduces doxorubicin cardiotoxicity (10). These results would hold great potential for clinical applications. In addition, the transgenic model produced in this study will present a valuable experimental approach to understanding mechanisms of other cardiac disease conditions. There is, for example, disagreement on whether ischemia-reperfusion induced heart damage is mediated by oxidative stress. This experimental model should provide an appropriate tool to address this question.

\section{Acknowledgments}

The authors thank Dr. Jeffrey Robbins at the University of Cincinnati College of Medicine for providing the alpha cardiac myosin heavy chain promoter construct and Dr. John S. Lazo at the Univer- 
sity of Pittsburgh for providing the human MT-IIa gene construct. The authors also thank Judith Alexander and Bo Xu for technical assistance.

This work was supported in part by National Institutes of Health grants CA63752 and CA68125 (Y.J. Kang) and DK44519 (P.N. Epstein), and a Grant-in-Aid from the American Heart Association 947070 (Y.J. Kang). Y.J. Kang is a University scholar of the University of Louisville, and a recipient of the American Heart Association Established Investigator award (9640091N).

\section{References}

1. Von Hoff, D.D., M.W. Layard, P. Basa, H.L. Davis, A.L. Von Hoff, M. Rozencweig, and F.M. Muggia. 1979. Risk factors for doxorubicin-induced congestive heart failure. Ann. Intern. Med. 91:710-717.

2. Buzdar, A.U., C. Marcus, T.L. Smith, and G.R. Blumenschein. 1985. Early and delayed clinical cardiotoxicity of doxorubicin. Cancer. 55:2761-2765.

3. Ferrans, V.J., 1978. Overview of cardiac pathology in relation to anthracycline cardiotoxicity. Cancer Treat. Rep. 62:955-961.

4. Keizer, H.G., H.M. Pinedo, G.J. Schuurhuis, and H. Joenje. 1990. Doxorubicin (Adriamycin): A critical review of free radical-dependent mechanisms of cytotoxicity. Pharmacol. Ther. 47:219-231.

5. Gianni, L., and C.E. Myers. 1992. The role of free radical formation in the cardiotoxicity of anthracycline. In Cancer Treatment and the Heart. F.M. Muggia, M.D. Green, and J.L. Speyer, editors. The Johns Hopkins University Press, Baltimore and London. 9-46.

6. Lee, V., A.K. Randhawa, and P.K. Singal. 1991. Adriamycin-induced myocardial dysfunction in vitro is mediated by free radicals. Am. J. Physiol. 261:H989-H995.

7. Myers, C.E., W.P. McGuire, R.H. Liss, K. Grotzinger, and R.C. Young. 1977. Adriamycin: the role of lipid peroxidation in cardiac toxicity and tumor response. Science (Wash. DC). 197:165-167.

8. Hamer, D.H., 1986. Metallothionein. Ann. Rev. Biochem. 55:913-951.

9. Thornalley, P.J., and M. Vasak. 1985. Possible role for metallothionein in protection against radiation-induced oxidative stress. Kinetics and mechanism of its reaction with superoxide and hydroxyl radicals. Biochim. Biophys. Acta. 827:36-44

10. Satoh, M., A. Naganuma, and N. Imura. 1988. Metallothionein induction prevents toxic side effects of cisplatin and adriamycin used in combination. Cancer Chemother. Pharmacol. 21:176-178.

11. Karin, M., and R.I. Richards. 1982. Human metallothionein genes-primary structure of the metallothionein-II gene and a related processed gene. $\mathrm{Na}$ ture (Lond.). 299:797-802.

12. Gulick, J., A. Subramaniam, J. Neumann, and J. Robbins. 1991. Isolation and characterization of the mouse cardiac myosin heavy chain genes. $J$. Biol. Chem. 266:9180-9185.

13. Hogan, B., F. Constantini, and E. Lacy. 1986. Manipulating the mouse embryo. Cold Spring Harbor Laboratory, New York. 332 pp.

14. Willis, E.H., E.R. Mardis, W.L. Jones, and M.C. Little. 1990. Prep-A-Gene, a superior matrix for the purification of DNA and DNA fragments. BioTechniques. 9:92-99.

15. Taketo, M., A.C. Schroeder, L.E. Mobraaten, K.B. Gunning, G.
Hanten, R.R. Fox, T.H. Roderick, C.L. Stewart, F. Lilly, C.T. Hansen, and P.A. Overbeek. 1991. Proc. Natl. Acad. Sci. USA. 88:2065-2069.

16. Eaton, D.L., and M.G. Cherian. 1991. Determination of metallothionein in tissues by cadmium-hemoglobin affinity assay. Methods Enzymol. 205:83-88.

17. Nebot, C., M. Moutet, P. Huet, J.-Z. Xu, J.-C. Yadan, and J. Chaudiere. 1993. Spectrophotometric assay of superoxide dismutase activity based on the activated autoxidation of a tetracyclic catechol. Anal. Biochem. 214:442-451.

18. Aebi, H., 1984. Catalase in vitro. Methods Enzymol. 105:121-127.

19. Smith, P.K., R.I. Krohn, G.T. Hermanson, A.K. Mallia, F.H. Gartner, M.D. Proverzano, E.K. Fujimoto, N.M. Goeke, B.J. Olson, and D.C. Klerk 1985. Measurement of protein using bicinchoninic acid. Anal. Biochem. 150:7685.

20. Flohe, L., and W.A. Gunzler. 1984. Assays of glutathione peroxidase Methods Enzymol. 105:114-121.

21. Carlberg, I., and B. Mannervik. 1985. Glutathione reductase. Methods Enzymol. 113:484-490.

22. Tietze, F. 1969. Enzymic method of quantitative determination of nonogram amounts of total and oxidized glutathione: application to mammalian blood and other tissues. Anal. Biochem. 57:502-522.

23. Oliver, I.T. 1963. A spectrophotometric method for the determination of creatine kinase. J. Lab. Clin. Med. 62:159-164.

24. Bachur, N.R., S.L. Gordon, and M.W. Gee. 1978. A general mechanism for microsomal activation of quinone anticancer agents to free radicals. Cancer Res. 38:1745-1750.

25. Kalyanaraman, B., R.C. Sealy, and B.K. Sinha. 1984. An electron spin resonance study of the reduction of peroxides by anthracycline semiquinones. Biochim. Biophys. Acta. 779:270-275.

26. Olson, R.D., R.C. Boerth, J.G. Gerber, and A.S. Nies. 1981. Mechanism of adriamycin cardiotoxicity: Evidence for oxidative stress. Life Sci. 29:13931401.

27. Powell, S.R., and P.B. McCay. 1988. Inhibition of doxorubicin-initiated membrane damage by $\mathrm{N}$-acetylcysteine: Possible mediation by a thiol-dependent, cytosolic inhibitor of lipid peroxidation. Toxicol. Appl. Pharmacol. 96 175-184.

28. Hida, H., C. Coudray, J. Calop, and A. Favier. 1995. Effect of antioxidants on adriamycin-induced microsomal lipid peroxidation. Biol. Trace Elem. Res. 47:111-116.

29. Julicher, R.H.M., A. van der Laarse, L. Sterrenberg, C.H.F. Bloys van Treslong, A. Best, and J. Noordhoek. 1985. The involvement of an oxidative mechanism in the adriamycin induced toxicity in neonatal rat heart cell cultures. Res. Comm. Chem. Pathol. Pharmacol. 47:35-47.

30. Lazo, J.S., and B.R. Pitt. 1995. Metallothioneins and cell death by anticancer drugs. Annu. Rev. Pharmacol. Toxicol. 35:635-653.

31. Thomas, J.P., G.L. Bachowski, and A.W. Girotti. 1986. Inhibition of cell membrane lipid peroxidation by cadmium- and zinc-metallothionein. Biochem. Biophys. Acta. 884:448-461.

32. Chvapil, M., J.N. Ryam, and C.F. Zukoshi. 1972. Effect of zinc on lipid peroxidation in liver microsomes and mitochondria. Proc. Soc. Exp. Biol. Med. 141:150-153.

33. Good, M., and M. Vasak. 1986. Spectroscopic properties of the cobalt(II)-substituted alpha-fragment of rabbit liver metallothionein. Biochemistry. 25:8353-8356.

34. Kang, Y.J., Y. Chen, and P.N. Epstein. 1996. Suppression of doxorubicin cardiotoxicity by overexpression of catalase in the heart of transgenic mice. J. Biol. Chem. 271:12610-12616. 